\title{
UK bans, Health Canada warns about antidepressants
}

Six months after the UK banned antidepressant drugs for children, Health Canada has issued a warning that using 7 of the medications may make patients worse.

Patients of all ages taking fluvoxamine (Luvox), paroxetine (Paxil), sertraline (Zoloft), mirtazapine (Remeron), fluoxetine (Prozac) and citalopram (Celexa), as well as those taking bupropion as an antidepressant (Wellbutrin) or smoking cessation drug ( $\mathrm{Zy}$ ban) may "experience behavioural and/or emotional changes that may put them at increased risk of self-harm or harm to others," Health Canada cautioned June 4 in a directive to physicians and consumers.

Recent studies have indicated that selective serotonin reuptake inhibitors (SSRIs) or serotonin $\vec{\infty}$ noradrenalin reuptake inhibitors (SNRIs) may worsen depression or trigger suicidal or aggressive impulses.

In December 2003, the UK banned the use of 4 antidepressants for children; it had banned 2 others earlier last year. The US
Food and Drug Administration followed on March 22 with a strongly worded warning about the drugs.

But the chair of a 5-member expert advisory panel Health Canada convened to assess SSRIs does not believe the evidence supports a Britishstyle ban or a stronger warning, he says. The more "measured" Canadian response puts the issue in proper perspective for physicians, says Dr. Yvon Lapierre. "There is some evidence that maybe this is happening, sufficient to give you this warning, but not to remove it from the market."

Manufacturers will be required to amend their product monographs, patients will be notified through an information sheet accompanying their prescriptions, and physicians will receive letters informing them of the risk, says Health Canada spokesperson Jirina Vlk.
Patients who experience suicidal impulses or feelings of agitation, hostility or anxiety are urged to consult their doctor rather than discontinuing the medication abruptly, which may provoke serious withdrawal symptoms.

"The Americans have taken the same attitude as we have in Canada: be careful," says Lapierre. "Treat your patients properly. Keep an eye on them and you shouldn't have any problems."

An article by Lapierre ( 7 Psychiatry Neurosci 2003;28[5]:3407) concluded there is little evidence that SSRIs cause increased suicidality.

The delay in Health Canada's response to concerns about the drugs was necessary, says Vlk, because reviewers examined more than 70 brand-name and generic versions of the medications licensed in Canada. Wayne Kondro, Ottawa

\section{Pharmaceutical Lawsuit}

\section{Legal action against GSK over SSRI data}

The New York State Attorney is suing GlaxoSmithKline (GSK) over its alleged failure to disclose important safety and efficacy information concerning the use of its antidepressant paroxetine (Paxil in North America and Seroxat in the UK) by people under 18 .

The case arose after a confidential GSK memo leaked to media (CMA7 2004;170[5]:783) documented a 1998 clinical trial that concluded paroxetine had no beneficial effect in the treatment of adolescents. The authors of the report recommended GSK "effectively manage the dissemination of these data in order to minimize any potential negative commer- cial impact." Sales for paroxetine totalled nearly $\$ 4.97$ billion worldwide in 2003.

The US and UK have already taken action (see above).

The New York State Attorney General announced June 2 it has filed a consumer fraud lawsuit against GSK for allegedly engaging in "repeated and persistent fraud by concealing and failing to disclose to physicians certain information about Paxil...."

The concealed information “impaired doctors' ability to make the appropriate prescribing decision for their patients and may have jeopardized public health and safety," stated Attorney General Eliot Spitzer.

The state attorney's office is seeking restitution for New York State residents who bought paroxetine for their children. Rose Firestein, the lawyer handling the case, isn't sure how much that would total. At the earliest, the case will get to court within a year.

In a public statement, GSK said it has "acted responsibly ... in disseminating data from [pediatric] studies." It says the leaked memo "is inconsistent with the facts and does not reflect the company position."

In the UK, meanwhile, officials at the Medicines and Healthcare Products Regulatory Agency are investigating GSK over similar concerns. Barbara Sibbald, CMAJ 